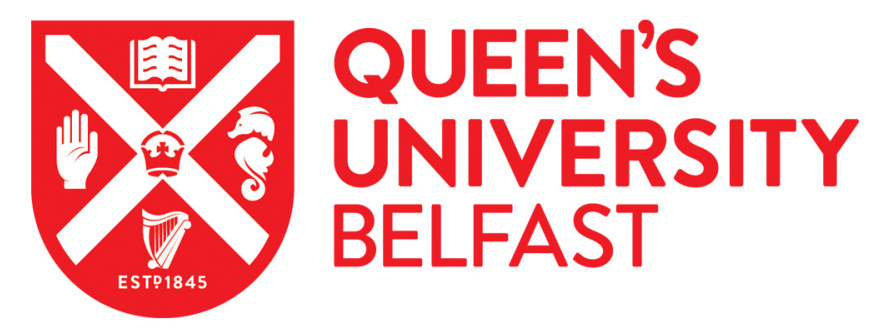

\title{
Overweight duration in older adults and cancer risk: a study of cohorts in Europe and the United States
}

Arnold, M., Freisling, H., Stolzenberg-Solomon, R., Kee, F., O'Doherty, M. G., Ordóñez-Mena, J. M., Wilsgaard, T., May, A. M., Bueno-de-Mesquita, H. B., Tjønneland, A., Orfanos, P., Trichopoulou, A., Boffetta, P., Bray, F., Jenab, M., Soerjomataram, I., \& CHANCES consortium (2016). Overweight duration in older adults and cancer risk: a study of cohorts in Europe and the United States. European Journal of Epidemiology.

https://doi.org/10.1007/s10654-016-0169-z

Published in:

European Journal of Epidemiology

Document Version:

Peer reviewed version

Queen's University Belfast - Research Portal:

Link to publication record in Queen's University Belfast Research Portal

Publisher rights

(C) 2016 Springer.

The final publication is available at Springer via http://dx.doi.org/[insert DOI]

General rights

Copyright for the publications made accessible via the Queen's University Belfast Research Portal is retained by the author(s) and / or other copyright owners and it is a condition of accessing these publications that users recognise and abide by the legal requirements associated with these rights.

Take down policy

The Research Portal is Queen's institutional repository that provides access to Queen's research output. Every effort has been made to ensure that content in the Research Portal does not infringe any person's rights, or applicable UK laws. If you discover content in the Research Portal that you believe breaches copyright or violates any law, please contact openaccess@qub.ac.uk. 


\section{OVERWEIGHT DURATION IN OLDER ADULTS AND CANCER RISK: A STUDY OF COHORTS IN EUROPE AND THE UNITED STATES}

Melina Arnold ${ }^{1}$, Heinz Freisling ${ }^{2}$, Rachael Stolzenberg-Solomon ${ }^{3}$, Frank Kee ${ }^{4}$, Mark G O'Doherty ${ }^{4}$, José M Ordóñez-Mena ${ }^{5,6}$, Tom Wilsgaard ${ }^{7}$, Anne M May ${ }^{8}, \mathrm{H}_{\text {Bas Bueno-de-Mesquita }}{ }^{9-12}$, Anne Tjønneland ${ }^{13}$, Philippos Orfanos ${ }^{14}$, Antonia Trichopoulou ${ }^{14,15}$, Paolo Boffetta ${ }^{14,16}$, Freddie Bray ${ }^{1}$, Mazda Jenab ${ }^{17}$, and Isabelle Soerjomataram ${ }^{1}$ on behalf of the CHANCES consortium

1. Section of Cancer Surveillance, International Agency for Research on Cancer, 150 Cours Albert Thomas, 69008 Lyon, France

2. Section of Nutrition and Metabolism, Dietary Exposure Assessment Group, International Agency for Research on Cancer, 150 Cours Albert Thomas, 69008 Lyon, France

3. Division of Cancer Epidemiology \& Genetics, Nutritional Epidemiology Branch, National Cancer Institute (NCI/DCEG), 9609 Medical Center Drive, Bethesda, Maryland 20892, USA

4. UKCRC Centre of Excellence for Public Health, School of Medicine, Dentistry and Biomedical Sciences, Queen's University Belfast, University Road Belfast, BT7 1NN, Northern Ireland, UK

5. Network Aging Research (NAR), Heidelberg University, Bergheimer Straße 20, 69115 Heidelberg, Germany

6. Division of Clinical Epidemiology and Aging Research, German Cancer Research Center (DKFZ), Im Neuenheimer Feld 581, 69120 Heidelberg, Germany

7. Department of Community Medicine, The Arctic University of Norway, 9037 Troms $\varnothing$, Norway

8. University Medical Center Utrecht, Juliu Center for Health Sciences and Primary Care, Epidemiology, Utrecht, The Netherlands

9. Department for Determinants of Chronic Diseases (DCD), National Institute for Public Health and the Environment (RIVM), PO Box 1, 3720 BA Bilthoven, The Netherlands

10. Department of Gastroenterology and Hepatology, University Medical Centre, Huispost Str. 6.131, 3508 GA Utrecht, The Netherlands

11. Department of Epidemiology and Biostatistics, The School of Public Health, Imperial College London, London, United Kingdom

12. Department of Social \& Preventive Medicine, Faculty of Medicine, University of Malaya, Kuala Lumpur, Malaysia

13. Danish Cancer Society Research Center, Strandboulevarden 49, 2100 Copenhagen $\varnothing$, Denmark

14. Hellenic Health Foundation, 13 Kaisareias \& Alexandroupoleos, Athens 115 27, Greece

15. Department of Hygiene, Epidemiology and Medical Statistics, University of Athens Medical School, Mikras Asias 75, Athens 115 27, Greece

16. Institute for Translational Epidemiology and Tisch Cancer Institute, Icahn School of Medicine at Mount Sinai, One Gustave L. Levy Place, Box 1128, New York, NY 10029-6574, USA

17. Section of Nutrition and Metabolism, Nutritional Epidemiology Group, International Agency for Research on Cancer, 150 Cours Albert Thomas, 69008 Lyon, France 


\section{Correspondence to:}

Melina Arnold, PhD

Section of Cancer Surveillance

International Agency for Research on Cancer

150 Cours Albert Thomas

69008 Lyon

FRANCE

Phone: $\quad+33(0) 472738400$

Fax: $\quad+33(0) 472738696$

Mail: $\quad$ arnoldm@iarc.fr 
ABSTRACT (246 words)

Recent studies have shown that cancer risk related to overweight and obesity is mediated by time and might be better approximated by using life years lived with excess weight. In this study we aimed to assess the impact of overweight duration and intensity in older adults on the risk of developing different forms of cancer. Study participants from seven European and one US cohort study with two or more weight assessments during follow-up were included $(n=329,576)$. Trajectories of body mass index (BMI) across ages were estimated using a quadratic growth model; overweight duration (BMI 225$)$ and cumulative weighted overweight years were calculated. In multivariate Cox models and random effects analyses, a longer duration of overweight was significantly associated with the incidence of obesityrelated cancer (overall Hazard Ratio (HR) per 10-yr increment: 1.36; 95\% Cl: 1.12-1.60), but also increased the risk of postmenopausal breast and colorectal cancer. Additionally accounting for the degree of overweight further increased the risk of obesity-related cancer. Risks associated with a longer overweight duration were higher in men than in women and were attenuated by smoking. For postmenopausal breast cancer, increased risks were confined to women who never used hormone therapy. Overall, $8.4 \%$ of all obesity-related cancers could be attributed to overweight at any age. These findings provide further insights into the role of overweight duration in the etiology of cancer and indicate that weight control is relevant at all ages. This knowledge is vital for the development of effective and targeted cancer prevention strategies.

Keywords: CHANCES; Ageing; Cohort; Obesity; Cancer; Prevention 


\section{INTRODUCTION}

Obesity has emerged as one of the most prevalent risk factors for non-communicable diseases and is still on the rise in many populations.(1, 2) Currently about $69 \%$ of all US adults are considered overweight or obese (body mass index, $\mathrm{BMI} \geq 25 \mathrm{~kg} / \mathrm{m}^{2}$ ) and $35 \%$ obese $\left(\mathrm{BMI} \geq 30 \mathrm{~kg} / \mathrm{m}^{2}\right)$, making it one of the countries with the highest prevalence of obesity in the world.(2,3) Even though the level of obesity has been catching up in Western Europe over the past two decades, obesity prevalence is still presently lower than in North America, 20\% in 2008.(4) In addition, overweight has become a growing problem specifically in the elderly, the fastest growing population segment in most high-income countries. For example, both in Europe and in the US, women aged 60 and above are more likely to be overweight or obese than any other age group. $(3,5)$

These developments have come at the cost of parallel rises in obesity-related morbidities, health care expenditures and mortality, most notably from cardio-vascular diseases and cancer.(6) In 2012, nearly half a million cancer cases globally were attributable to high BMI; more than half of this burden occurred in higher-income regions, most notably in Europe and Northern America.(7) These disparities across countries and regions not only reflect varying levels of obesity, but also differences in the strength of the cancer-obesity association between populations and in the prevalence and distribution of other risk factors modifying the association, such as smoking, diabetes and the use of hormone therapy $(H T) .(8,9)$ Although the link between obesity and cancer is well-documented (8), most studies investigating this association are based on single measurements of height and weight at one point in life and evidence on the cumulative effects of overweight during the life course on disease risk remains scarce. Yet recent studies have shown that obesity duration is an important and independent predictor of type 2 diabetes (10), cardio-vascular disease (11) and all-cause mortality (12). Given that a longer exposure to overweight increases the risk and severity of insulin resistance, chronic inflammation, oxidative DNA damage and alterations in endogenous hormone levels (13) - all of which are thought to be cancer promotive - overweight duration may be an important, but also yet understudied, predictor of the risk of cancer development.

In this study, we assessed the impact of overweight duration and intensity on cancer risk in more than 300,000 older adults in a pooled dataset of seven European and one US prospective cohort studies. In secondary analyses, we evaluated the effects of important effect modifiers and confounders including sex, smoking status, diabetes and HT. 


\section{MATERIALS AND METHODS}

\section{Study design and participants}

This study uses repeated anthropometric assessments obtained from seven European (EPIC Elderly Denmark, Greece, Netherlands, and Spain; ESTHER, Germany; PRIME Belfast, Northern Ireland; Troms $\varnothing$, Norway) and one American cohort study (NIH AARP), pooled as part of the Consortium of Health and Aging: Network of Cohorts in Europe and the United States (CHANCES, www.chancesfp7.eu). A selection of the cohorts' key characteristics is shown in Table 1. Additional information on the individual cohorts has been described elsewhere.(14) All CHANCES cohort studies are conducted in accordance with the Declaration of Helsinki. For each study, investigators satisfied the local requirements for ethical research, including obtaining informed consent from participants.

Patients with a history of cancer at baseline $(n=11,710)$ or an unknown study exit $(n=418)$ were excluded. Furthermore, for inclusion in this study, participants were required to have at least two valid $\mathrm{BMI}$ assessments during follow-up, including baseline and excluding assessments after or in the year preceding cancer diagnosis. For NIH AARP, participants with a retrospective self-reported BMI at age 50 and height and weight assessments at baseline were included. Missing data on either smoking or physical activity status at baseline were excluded $(n=16,398))$. The derivation of the final number of included persons by study is portrayed in Figure 1.

\section{Outcomes}

Incident cancer cases were identified through linkage to cancer registries (EPIC NL, EPIC DK, NIH AARP, Troms $\varnothing$ ) or through self-reports that were confirmed by medical records and/or pathology reports (ESTHER, PRIME Belfast) or both (EPIC Spain, EPIC Greece). Analyses were conducted for cancer sites where convincing evidence of a positive association with excess BMI was reported. $(8,15)$ We examined invasive breast cancer (ICD-O-3 C50) at postmenopausal ages, colorectal cancer (C18-21), as well as a combined obesity-related cancer category that also included cancer of the lower oesophagus (C15.5, as a proxy for oesophageal adenocarcinoma in the absence of histological data), gastric cardia (C16.0), liver (C22), gallbladder (C23), pancreas (C25), , endometrium (C54), ovary (C56) and kidney (C64)

\section{Exposure variables}

Overweight was defined as having a BMI above $25 \mathrm{~kg} / \mathrm{m}^{2}$. BMI values below $15 \mathrm{~kg} / \mathrm{m}^{2}$ and above 45 $\mathrm{kg} / \mathrm{m}^{2}$ were considered highly unlikely and hence considered as missing. For all European studies except 
ESTHER, where only self-reported anthropometry was available, BMI at baseline was calculated based on measured height and weight. At re-contact, data on height and weight were self-reported in all cohorts, except PRIME Belfast and Troms $\varnothing$ where BMI at follow-up was based on measured anthropometry. In NIH AARP, height and weight were self-reported at age 50 (retrospectively) and at baseline. Supplementary Figure 1 provides an overview of the study-specific timing of repeated anthropometric measurements by cohort.

\section{Covariates}

Baseline information on all covariates except alcohol consumption (continuous, grams/day) were available as categorical variables as follows: (daily) smoking status (never smoker/former smoker/current smoker), vigorous physical activity (yes/no, for performing intense exercise at least once a week), highest level of education (primary or less/more than primary but less than college or university/college or university), HT use (never/ever). Other information on reproductive history and diet were not consistently available in all cohorts and could not be taken into account in our analyses.

\section{Statistical analysis}

The analysis was carried out in three steps. First, a quadratic growth model with a random intercept and random slope was used to predict individual BMI trajectories for each study participant. $(16,17)$ This model was developed and adjusted in a step-wise manner by adding study, sex, smoking status, physical activity and an interaction term for study and contact age to the fixed effects part of the model. The obtained predicted BMI values for all ages between study entry (baseline) and study exit were then used to estimate overweight ( $\mathrm{BMI} \geq 25$ ) duration in years. Weighted cumulative overweight years (OWY) were computed by multiplying the duration of overweight in years by the difference (in BMI units) above normal $\mathrm{BMI}(\mathrm{BMI} \geq 25)$ for each increment of age. This measure takes into account the degree of overweight over time and is comparable to pack-years in relation to tobacco smoking. For example, when considering 10 years of follow-up, a person with $\mathrm{BMI}=26$ would accumulate 10 OWY $(26-25 * 10)$ and 10 years of overweight duration; a person with a $\mathrm{BMI}=35$ would accumulate 100 OWY (35-25*10). Overweight duration was assessed per 10-year increment and cumulative OWY per 100 units.

Secondly, Cox proportional hazard models with age as time metric were used to estimate hazard ratios (HR) and 95\% confidence limits (Cl) to describe the relation between overweight duration, cumulative OWY and the risk of developing cancer. Overweight duration and cumulative OWY were treated as continuous, time-dependent covariates in the model. Baseline information was used for all other 
covariates. Subjects were censored at death, lost to follow-up (i.e. emigration, opt-out), any cancer excluding non-melanoma skin cancer (C44) diagnosis other than the site of interest or cohort-specific end-of-follow up, whichever occurred first. For all outcomes, three models with different sets of adjustments were fitted. In model 1, adjustments were made for sex. Model 2 was additionally adjusted for smoking status and physical activity. In model 3, further adjustments were made for education and alcohol consumption. The proportional hazard assumptions were assessed by visual inspection of log-log plots and by statistical tests using Schoenfeld residuals. Any covariates for which proportional hazards were unlikely were stratified, but the final results were not materially different from the unstratified models.

All analyses were carried out for each study separately and the results were then combined using random-effects meta-analysis in order to limit the influence of study size (especially with regard to the NIH AARP cohort). (18) Data from all cohorts were then pooled to describe the dose-response relationship between overweight duration, intensity and cancer risk and to assess interactions in stratified analyses by sex, smoking status, HT use and diabetes history. We used restricted cubic splines with four knots at Harrell's default percentiles to model non-linear relations between obesity duration, OWY and cancer risk. Analyses of the pooled data were additionally adjusted for study.

Lastly, and based on the assumption that the association between overweight and the cancer sites included in our study is causal (19), population attributable fractions (PAF) and their $95 \% \mathrm{Cls}$ were calculated $(20,21)$ using the maximum likelihood method $(22)$ and the 'punaf' command in Stata. PAFs represent the proportion of obesity-related cancer cases that could have been avoided if participants were never overweight during follow-up.

All statistical analyses were performed using Stata 12. 


\section{RESULTS}

In total, 329576 participants were included in this study, with 16520 obesity-related cancer cases occurring during follow-up (Table 1). Study participants were recruited between 1991 and 2003, with a mean age at study entry ranging from 54 years in Northern Ireland (PRIME Belfast) cohort to 67 years in Greece (EPIC elderly). Education level (highest attained degree) was particularly high in the US (NIH AARP) (75\% with college or university degree), while more than $85 \%$ of the Spanish participants (EPIC elderly) had only primary education or less. Mean BMI at baseline ranged between $25.8 \mathrm{~kg} / \mathrm{m}^{2}$ in the Netherlands to $29.5 \mathrm{~kg} / \mathrm{m}^{2}$ in Spain, where $42 \%$ of the study participants were classified as obese (BMI $\geq 30$ ). While $75 \%$ of all participants from Denmark (EPIC elderly) reported to be physically active, this applied to only $5 \%$ in Spain. Alcohol intake was highest in Denmark $(20.2 \mathrm{~g} / \mathrm{d})$ and lowest in Norway (Troms $\varnothing-3.6 \mathrm{~g} / \mathrm{d}$ ), in contrast with smoking, where Norway had the highest and Greece the lowest proportion of current daily smokers (31\% and 12\% respectively). Median follow-up ranged between 10.4 years in Germany (ESTHER) and 18.0 years in Northern Ireland (PRIME Belfast). Age-standardized incidence rates of obesity-related cancers ranged between 351 per 100000 person-years in the US to 45 per 100000 in Greece.

In the meta-analysis of all studies, a longer duration of overweight was significantly associated with an increased risk of obesity-related cancer combined (Hazard Ratio (HR) per 10-yr increment: 1.36; 95\%Cl: 1.12 to 1.60 ) and was most pronounced in the German ESTHER cohort (HR: 2.29, 95\% Cl: 1.66 to 3.14), but not statistically significant in the Spanish and Danish EPIC cohorts and PRIME Belfast (Figure 2). When taking the degree of overweight over time into account, risks tended to be slightly more pronounced, especially in the US NIH AARP cohort (Figure 2), but also overall (HR per 100-unit increment in OWY: 1.46; 95\% $\mathrm{Cl}: 1.14$ to 1.77). While results were similar for postmenopausal breast and colorectal cancer, higher risks were found for other obesity-related sites, comprising cancer of the pancreas, kidney, gallbladder and endometrium. HRs for the association between overweight duration and cumulative OWY by cancer site and cohort, for the different models are presented in Supplementary Table 1. As adjustments for alcohol consumption and education level in model 3 only marginally altered the results of model 2 , the latter simpler model was used when exploring doseresponse relationships between increasing overweight duration, intensity and cancer risk. Clear associations were found for all obesity-related cancer sites combined, but also for breast cancer in HT non-users (Figure 3, panel A). When taking into account the degree of overweight over time, the risk increase became more pronounced, especially for other obesity-related cancers (Figure 3, panel B). This 
relationship was mainly driven by kidney and endometrial cancer, showing exponential associations with the combination of overweight duration and intensity over time (data not shown).

The population attributable fraction (PAF) for ever being overweight during follow-up was $8.4 \%$ (95\% $\mathrm{Cl}$ : 6.3 to $10.5 \%$ ) for obesity-related cancers combined (Table 2). PAFs were considerably higher in men than in women $(20.0 \%$ vs $4.6 \%)$, in never smokers relative to current and past smokers and in those with a history of diabetes type 2 . In women who never used HT, $15.6 \%$ (11.8 to 19.2\%) of all breast cancers were attributable to ever being overweight during follow-up.

In secondary analyses, we investigated the potential confounding effects of sex, smoking status, HT use and diabetes history in the pooled dataset (Supplementary Table 2). Generally, the risks associated with both overweight duration and cumulative OWY were higher in men than in women. After stratification for sex, the risk of colorectal cancer associated with a longer overweight duration and intensity (OWY) reached statistical significance in both men and women. Gradients in risk were found across smoking categories, indicating that the risk of obesity-related cancer due to overweight duration and/or cumulative OWY was highest among never smokers, intermediate among former smokers and low or negligible in current smokers. For breast cancer, significantly increased risks were observed in women who never used $\mathrm{HT}$, with similar effect sizes for both overweight duration (HR: 1.41, 95\%Cl: 1.25 to 1.58) and cumulative OWY (HR: 1.33, 95\% Cl: 1.15 to 1.53). Risks of obesity-related cancers were higher in study participants who ever reported type 2 diabetes relative to those who had no diabetes history, especially when the degree of overweight over time was taken into account. 


\section{DISCUSSION}

Based on a pooling of eight cohort studies, 300000 participants and more than 16000 obesity-related cancers, this is the first study to assess the impact of overweight duration on cancer risk in older populations. Overall, we found that a longer duration of overweight was significantly associated with a higher risk of postmenopausal breast and colorectal cancer, as well as for obesity-related cancers combined. Risks associated with a longer overweight duration were higher in men than in women and among non-smokers than in current smokers. For post-menopausal breast cancer, increased risks were confined to women who never used HT. When additionally taking the degree of overweight over time into account, risks increased even further. Overall, $8.4 \%$ of obesity-related cancers could be attributed to being overweight at any time point after age 50 (10.7\% in never smokers).

These findings are consistent with studies reporting associations between high BMI at one point in time and cancer risk $(8,23)$ and are in line with evidence on the impact of obesity duration on other health outcomes, including type 2 diabetes, cardiovascular disease and all-cause mortality.(10-12) One of the putative underlying biological mechanisms involves changes in the metabolism of sex-steroid hormones, namely oestrogen, which is mainly produced by fat tissue in postmenopausal women.(24) Hence, a longer overweight duration increases the exposure time to elevated hormone levels, which may in turn increase the risk of developing cancer. In our study, we found that the increased risk of postmenopausal breast cancer related to a longer overweight duration was confined to women who never used HT and risks were similar for overweight duration and OWY. This finding suggests that exogenous oestrogen and hormone levels modify the association between overweight duration and postmenopausal breast cancer, as noted in previous studies. $(25,26)$ While similar associations have also been reported for endometrial cancer $(27,28)$, evidence for effect modification for colorectal cancer is inconsistent across studies. $(29,30)$

We also noted important sex differences in the risk of developing obesity-related cancer associated with increasing overweight duration. Higher risks in men were mainly evident for colorectal cancer and all obesity-related cancers combined. This is consistent with previous studies pointing towards a stronger link between different measures of obesity and colorectal cancer in men, with the association much weaker or absent in women. $(31,32)$ Increased waist circumference has been suggested to be a better predictor of colorectal cancer risk than BMI that varies markedly by sex.(32, 33) Waist circumference is a proxy for visceral adipose tissue, where leptin and adiponectin are predominantly secreted. Adiponectin is inversely correlated with body fatness, is anti-inflammatory and inhibits tumour growth 
in animals.(34) As circulating levels of adiponectin have been found to be higher in women than men, this may offer an explanation for sex differences in colorectal cancer risk associated with overweight and obesity.(31) When assessing the dose-response relationship between overweight duration and cancer risk, we also noted that peaks in risk differed by cancer site, possibly reflecting early and late promotional effects of adiposity for some cancers. Yet, the site specific numbers of cases were too small to draw firm conclusion from this finding.

Another important confounder was smoking. We found that the effect of increasing overweight duration on the risk of developing obesity-related cancer was stronger in never smokers relative to current smokers. This association was more pronounced when the degree of overweight was taken into account, and is supported by previous findings on the role of smoking in the obesity-cancer pathway. (8, $35,36)$ Other factors such as hormones and circulating levels of DNA adducts have been suggested to contribute to lower risks of obesity-related cancers observed in smokers. (8, 37-39) In contrast, history of type 2 diabetes modified the overweight-cancer association in our study in a way that participants with a positive history had the greatest risk. This finding confirms previous findings on the interaction between overweight duration, diabetes and pancreatic cancer.(40)

While our findings were largely consistent across studies, we generally found weaker associations in the US cohort when compared to the European cohorts. The between-study heterogeneity could only marginally be reduced by accounting for sex, HRT use and smoking, suggesting that other (unmeasured) factors must be responsible for the differences observed across studies. At least in parts, this may also be explained by differences in the baseline characteristics between European and US study participants as well as the respective study sizes. In comparison with the combined European cohorts, comprising 38 563 study participants, the US NIH AARP cohort was much larger (291 013 participants), and hence better powered. Additionally, the majority of the US NIH AARP participants were highly educated and less likely to be current smokers or physically inactive than participants of the European cohorts, limiting the generalizability of the findings to the general US population. Yet, given the similar associations found across the studies and the general notion that the effect of obesity on cancer development should not differ between Europeans and North Americans, we believe that our results are valid and most likely a conservative estimate of the true effect.

In the pooled analysis, we were able to include a large number of study participants from several European countries and the US, which enabled an assessment of the dose-response relationship between overweight duration and cancer risk, as well as related sensitivity analyses. However, some 
methodological considerations and limitations should be noted. In the first step of our analysis, we used repeated measurements and self-reports of height and weight to model BMI across ages using a growth curve model. With this approach, we were able to estimate each study participant's BMI trajectory and overweight duration during follow-up. When put into context with the observed BMI, the trajectories predicted by the model were fitting well, also owing to the fact that in most individuals BMI typically changes only marginally during adulthood (and if so, only slowly).(41, 42) As the results from the German ESTHER study (where only self-reported height and weight were available) were consistent with those from the other European cohorts (where BMI was calculated based on measured height and weight), we believe that the type of BMI information has not unduly affected our overall findings. When we repeated the analyses with obesity $(\mathrm{BMI} \geq 30)$ duration, the associations became slightly stronger. Due to the fact that there were no anthropometric data available before baseline (except in NIH AARP), we could only evaluate overweight duration and intensity after study entry, i.e. in the elderly, and could not take into account overweight earlier in life. This might have led to the unexpected shape of the dose-response curves (Figure 3), especially in the first years. Even though our results may not reflect risks on the individual-level (owing to the observational study design), the dose-response curves indicate that risk may be better approximated by taking both overweight duration and intensity into account.

It is furthermore important to note that BMI may not be an ideal measure of body fatness since it can reflect both adiposity and muscularity and is limited in its ability to predict body fatness across ethnic groups and age.(43) Age-related decreases in height might falsely lead to an increase in BMI and with advancing age fat tissue tends to be redistributed towards the abdominal region.(43) Hence, it might have been more appropriate to use one of the measures of central obesity as a surrogate for overweight and obesity as these have been suggested to better predict obesity-related health outcomes when compared to BMI. $(44,45)$ These measures were however not available longitudinally from the cohorts included in this study. Yet, in a companion paper using data from the same cohorts (except NIH-AARP), we found that the risk associated with a standard deviation increase in baseline BMI and waist circumference were similar for post-menopausal breast, colorectal and obesity-related cancers combined (Heinz Freisling, personal communication).

Further limitations of our study are related to differences in study design between cohorts, including differences in length of follow-up, anthropometric assessment methods and their frequency, as well as the comparability of several variables. In order to harmonize the data and variable definitions across cohorts, some variables such as physical activity were only available in binary form (yes/no). Despite 
adjustment for the main confounding factors, namely smoking and physical activity, we cannot rule out confounding by other unmeasured factors, most importantly reproductive risk factors and diet. As these were not consistently available from all cohorts, we were not able to take these into account in our analyses.

Lastly, it is important to acknowledge a number of methodological limitations, which we hope will prompt further research. In the same way that we have estimated cumulative exposure for our main independent variable, overweight duration, it may be surmised that the nature of the confounding or moderating effects of other exposures (such as smoking, alcohol intake or physical activity) might, in uncertain ways, depend on how their own cumulative effects have been modelled. Related to this is the fact that methodologists have recently debated about the correct way to model cumulative effects, when their effects on absolute rather than relative risk scales might differ and when more complex temporal patterns of exposure may not be modelled well on a proportional hazards scale. (46-48)

\section{Implications and conclusions}

We report that longer overweight duration increases the risk of cancer in older adults, in both Europe and the US, with $8.4 \%$ of obesity-related cancers attributable to overweight at any time point after age 50. Each of the studies included in this analysis was based on a prospective design, with data collection prior to disease onset. Thus, a degree of causality between overweight duration and cancer development can be inferred, although with great caution. These observations lend further credibility to existing clinical recommendations for weight reduction in the obese and the maintenance of healthy weight in the non-obese, irrespective of age. Avoidance of weight gain, engaging in physical activity, and even small amounts of weight loss have been suggested to prevent adverse health consequences of obesity in the elderly. $(43,49)$ Future studies should further investigate the specific roles of age at onset of overweight and different BMI trajectories on cancer risk. 


\section{ACKNOWLEDGEMENTS}

Collaborators on behalf of the CHANCES consortium: Migle Baceviciene, Jolanda M A Boer, Wojciech Drygas, Sture Eriksson, Edith Feskens, Valeriy Gafarov, Julian Gardiner, Niclas Hakansson, Jan-Hakan Jansson, Pekka Jousilahti, Ellen Kampman, Jukka Kontto, Ruzena Kubinova, Max Leenders, Allan Linneberg, Maja-Lisa Lochen, Roberto Lorbeer, Sofia Malyutina, Ellisiv B Mathiesen, Hakan Melhus, Karl Michaëlsson, Inger Njolstad, Nicola Orsini, Andrzej Pająk, Hynek Pikhart, Charlotta Pisinger, Veikko Salomaa, María-José Sánchez, Susana Sans, Barbara Schaan, Andrea Schneider, Galatios Siganos, Stefan Söderberg, Martinette Streppel, Abdonas Tamošiūnas, Giovanni Veronesi, Eveline Waterham, Patrik Wennberg.

Funding: Data used throughout the present study are derived from the CHANCES project. The project is coordinated by the Hellenic Health Foundation, Greece. The project received funding by the FP7 framework programme of DG-RESEARCH in the European Commission (grant agreement no. HEALTH-F32010-242244). EPIC Greece: funded by the Hellenic Health Foundation. EPIC Netherlands: funded by European Commission (DG SANCO); Dutch Ministry of Public Health, Welfare and Sports (VWS); The National Institute for Public Health and the Environment; the Dutch Cancer Society, the Netherlands Organisation for Health Research and Development (ZONMW); World Cancer Research Fund (WCRF). EPIC Spain: supported by Health Research Fund (FIS) of the Spanish Ministry of Health RTICC 'Red Temática de Investigación Cooperativa en Cáncer (grant numbers: Rd06/0020/0091 and Rd12/0036/0018), Regional Governments of Andalucía, Asturias, Basque Country, Murcia (project 6236), and Navarra, Instituto de Salud Carlos III, Redes de Investigacion Cooperativa (RD06/0020). ESTHER: funded by the Baden-Württemberg state Ministry of Science, Research and Arts (Stuttgart, Germany), the Federal Ministry of Education and Research (Berlin, Germany), and the Federal Ministry of Family Affairs, Senior Citizens, Women and Youth (Berlin, Germany). PRIME Belfast: supported by grants from the Institut National de la Santé et de la Recherche Médicale (INSERM), the Merck, Sharp \& DohmeChibret Laboratory and the Northern Ireland Health \& Social Care Research and Development Office. NIH-AARP: support for the National Institutes of Health (NIH)-AARP Diet and Health Study was provided by the Intramural Research Program of the National Cancer Institute (NCI), NIH. Troms $\varnothing$ : funded by: UiT The Arctic University of Norway, the National Screening Service, and the Research Council of Norway.

MA and IS were additionally supported by the World Cancer Research Fund International (grant number SG 2012/619). 
Conflict of interest statement: The authors declare no conflict of interest. 


\section{REFERENCES}

1. Finucane MM, Stevens GA, Cowan MJ, et al. National, regional, and global trends in body-mass index since 1980: systematic analysis of health examination surveys and epidemiological studies with 960 country-years and 9.1 million participants. Lancet. 2011;377(9765):557-67. doi:S01406736(10)62037-5 [pii]

\section{$10.1016 / \mathrm{S} 0140-6736(10) 62037-5$}

2. Collaboration. NRF, Di Cesare M, Bentham J, et al. Trends in adult body-mass index in 200 countries from 1975 to 2014: a pooled analysis of 1698 population-based measurement studies with 19.2 million participants. Lancet. 2016;387(10026):1377-96. doi:10.1016/S0140-6736(16)30054-X

3. Ogden CL, Carroll MD, Kit BK, Flegal KM. Prevalence of childhood and adult obesity in the United States, 2011-2012. JAMA. 2014;311(8):806-14. doi:10.1001/jama.2014.732

4. Stevens GA, Singh GM, Lu Y, et al. National, regional, and global trends in adult overweight and obesity prevalences. Popul Health Metr. 2012;10(1):22. doi:1478-7954-10-22 [pii]

$10.1186 / 1478-7954-10-22$

5. Overweight and obesity - BMI statistics [database on the Internet]. Eurostat. 2015 [cited 28-082015]. Available from: http://ec.europa.eu/eurostat/statisticsexplained/index.php?title=Overweight and obesity - BMI statistics\&oldid=120144.

6. Lakdawalla DN, Goldman DP, Shang B. The health and cost consequences of obesity among the future elderly. Health affairs. 2005;24 Suppl 2:W5R30-41. doi:10.1377/hlthaff.w5.r30

7. Arnold M, Pandeya N, Byrnes G, et al. Global burden of cancer attributable to high body-mass index in 2012: a population-based study. Lancet Oncol. 2015;16(1):36-46. doi:10.1016/S14702045(14)71123-4

8. Renehan AG, Tyson M, Egger M, Heller RF, Zwahlen M. Body-mass index and incidence of cancer: a systematic review and meta-analysis of prospective observational studies. Lancet. 2008;371(9612):569-78. doi:S0140-6736(08)60269-X [pii]

$10.1016 / \mathrm{S} 0140-6736(08) 60269-X$

9. Arnold $\mathrm{M}$, Leitzmann $\mathrm{M}$, Freisling $\mathrm{H}$, et al. Obesity and cancer: An update of the global impact. Cancer Epidemiol. 2016;41:8-15. doi:10.1016/j.canep.2016.01.003

10. Abdullah A, Stoelwinder J, Shortreed S, et al. The duration of obesity and the risk of type 2 diabetes. Public Health Nutr. 2011;14(1):119-26. doi:10.1017/S1368980010001813

11. Abdullah A, Amin FA, Stoelwinder J, et al. Estimating the risk of cardiovascular disease using an obese-years metric. BMJ open. 2014;4(9):e005629. doi:10.1136/bmjopen-2014-005629

12. Abdullah A, Wolfe R, Stoelwinder JU, et al. The number of years lived with obesity and the risk of all-cause and cause-specific mortality. Int J Epidemiol. 2011;40(4):985-96. doi:dyr018 [pii] 
10.1093/ije/dyr018

13. Bianchini F, Kaaks R, Vainio H. Overweight, obesity, and cancer risk. Lancet Oncol. 2002;3(9):565-74.

14. Boffetta P, Bobak M, Borsch-Supan A, et al. The Consortium on Health and Ageing: Network of Cohorts in Europe and the United States (CHANCES) project--design, population and data harmonization of a large-scale, international study. Eur J Epidemiol. 2014;29(12):929-36. doi:10.1007/s10654-014-

9977-1

15. Food, nutrition, physical activity and the prevention of cancer : a global perspective : a project of World Cancer Research Fund International. Washington, D.C.: American Institute for Cancer Research. World Cancer Research Fund.; 2007.

16. Heo M, Faith MS, Mott JW, Gorman BS, Redden DT, Allison DB. Hierarchical linear models for the development of growth curves: an example with body mass index in overweight/obese adults. Stat Med. 2003;22(11):1911-42. doi:10.1002/sim.1218

17. Naumova EN, Must A, Laird NM. Tutorial in Biostatistics: Evaluating the impact of 'critical periods' in longitudinal studies of growth using piecewise mixed effects models. Int J Epidemiol. 2001;30(6):1332-41.

18. Harris RJ, Bradburn MJ, Deeks JJ, Harbord RM, Altman DG, Sterne JAC. metan: fixed- and random-effects meta-analysis. Stata J. 2008;8(1):3-28.

19. Rockhill B, Newman B, Weinberg C. Use and misuse of population attributable fractions. Am J Public Health. 1998;88(1):15-9.

20. Hanley JA. A heuristic approach to the formulas for population attributable fraction. J Epidemiol Community Health. 2001;55(7):508-14.

21. Miettinen OS. Proportion of disease caused or prevented by a given exposure, trait or intervention. Am J Epidemiol. 1974;99(5):325-32.

22. Greenland S, Drescher K. Maximum likelihood estimation of the attributable fraction from logistic models. Biometrics. 1993;49(3):865-72.

23. Reeves GK, Pirie K, Beral V, et al. Cancer incidence and mortality in relation to body mass index in the Million Women Study: cohort study. BMJ. 2007;335(7630):1134.

doi:10.1136/bmj.39367.495995.AE

24. Calle EE, Kaaks R. Overweight, obesity and cancer: epidemiological evidence and proposed mechanisms. Nat Rev Cancer. 2004;4(8):579-91. doi:10.1038/nrc1408

25. Morimoto LM, White E, Chen Z, et al. Obesity, body size, and risk of postmenopausal breast cancer: the Women's Health Initiative (United States). Cancer Causes Control. 2002;13(8):741-51.

26. Food, Nutrition, Physical activity, and the Prevention of Breast Cancer. Continuous Update Project Report: World Cancer Research Fund / American Institute for Cancer Research2010. 
27. Reeves KW, Carter GC, Rodabough RJ, et al. Obesity in relation to endometrial cancer risk and disease characteristics in the Women's Health Initiative. Gynecol Oncol. 2011;121(2):376-82. doi:10.1016/j.ygyno.2011.01.027

28. Bhaskaran K, Douglas I, Forbes H, Dos-Santos-Silva I, Leon DA, Smeeth L. Body-mass index and risk of 22 specific cancers: a population-based cohort study of 5.24 million UK adults. Lancet. 2014. doi:10.1016/s0140-6736(14)60892-8

29. Wang $Y$, Jacobs EJ, Teras LR, et al. Lack of evidence for effect modification by estrogen of association between body mass index and colorectal cancer risk among postmenopausal women. Cancer Causes Control. 2007;18(8):793-9. doi:10.1007/s10552-007-9009-5

30. Slattery ML, Ballard-Barbash R, Edwards S, Caan BJ, Potter JD. Body mass index and colon cancer: an evaluation of the modifying effects of estrogen (United States). Cancer Causes Control. 2003;14(1):75-84.

31. Keimling M, Renehan AG, Behrens G, et al. Comparison of associations of body mass index, abdominal adiposity, and risk of colorectal cancer in a large prospective cohort study. Cancer Epidemiol Biomarkers Prev. 2013;22(8):1383-94. doi:10.1158/1055-9965.EPI-13-0353

32. Food, Nutrition, Physical activity, and the Prevention of Colorectal Cancer. Continuous Update Project Report: World Cancer Research Fund / American Institute for Cancer Research2011.

33. Ford ES, Li C, Zhao G, Tsai J. Trends in obesity and abdominal obesity among adults in the United States from 1999-2008. International journal of obesity. 2011;35(5):736-43. doi:10.1038/ijo.2010.186

34. Rose DP, Komninou D, Stephenson GD. Obesity, adipocytokines, and insulin resistance in breast cancer. Obes Rev. 2004;5(3):153-65. doi:10.1111/j.1467-789X.2004.00142.x

35. Smith L, Brinton LA, Spitz MR, et al. Body mass index and risk of lung cancer among never, former, and current smokers. J Natl Cancer Inst. 2012;104(10):778-89. doi:10.1093/jnci/djs179

36. Aune D, Greenwood DC, Chan DS, et al. Body mass index, abdominal fatness and pancreatic cancer risk: a systematic review and non-linear dose-response meta-analysis of prospective studies. Ann Oncol. 2012;23(4):843-52. doi:10.1093/annonc/mdr398

37. Henley SJ, Flanders WD, Manatunga A, Thun MJ. Leanness and lung cancer risk: fact or artifact? Epidemiology. 2002;13(3):268-76.

38. Calle EE, Rodriguez C, Walker-Thurmond K, Thun MJ. Overweight, obesity, and mortality from cancer in a prospectively studied cohort of U.S. adults. N Engl J Med. 2003;348(17):1625-38.

doi:10.1056/NEJMoa021423

$348 / 17 / 1625$ [pii]

39. Olson JE, Yang P, Schmitz K, Vierkant RA, Cerhan JR, Sellers TA. Differential association of body mass index and fat distribution with three major histologic types of lung cancer: evidence from a cohort of older women. Am J Epidemiol. 2002;156(7):606-15. 
40. Stolzenberg-Solomon RZ, Schairer C, Moore S, Hollenbeck A, Silverman DT. Lifetime adiposity and risk of pancreatic cancer in the NIH-AARP Diet and Health Study cohort. Am J Clin Nutr.

2013;98(4):1057-65. doi:10.3945/ajcn.113.058123

41. Ostbye $T$, Malhotra R, Landerman LR. Body mass trajectories through adulthood: results from the National Longitudinal Survey of Youth 1979 Cohort (1981-2006). Int J Epidemiol. 2011;40(1):240-50. doi:10.1093/ije/dyq142

42. Botoseneanu A, Liang J. Latent heterogeneity in long-term trajectories of body mass index in older adults. J Aging Health. 2013;25(2):342-63. doi:10.1177/0898264312468593

43. Decaria JE, Sharp C, Petrella RJ. Scoping review report: obesity in older adults. International journal of obesity. 2012;36(9):1141-50. doi:10.1038/ijo.2012.29

44. Moore LL, Bradlee ML, Singer MR, et al. BMI and waist circumference as predictors of lifetime colon cancer risk in Framingham Study adults. Int J Obes Relat Metab Disord. 2004;28(4):559-67. doi:10.1038/sj.ijo.0802606

45. Janssen I, Katzmarzyk PT, Ross R. Waist circumference and not body mass index explains obesity-related health risk. Am J Clin Nutr. 2004;79(3):379-84.

46. Peto J. That the effects of smoking should be measured in pack-years: misconceptions 4 . $\mathrm{Br} \mathrm{J}$ Cancer. 2012;107(3):406-7. doi:10.1038/bjc.2012.97

47. Hernan MA. The hazards of hazard ratios. Epidemiology. 2010;21(1):13-5. doi:10.1097/EDE.0b013e3181c1ea43

48. Thomas DC. Invited commentary: is it time to retire the "pack-years" variable? Maybe not! Am J Epidemiol. 2014;179(3):299-302. doi:10.1093/aje/kwt274

49. Zamboni M, Mazzali G, Zoico E, et al. Health consequences of obesity in the elderly: a review of four unresolved questions. International journal of obesity. 2005;29(9):1011-29.

doi:10.1038/sj.ijo.0803005 


\section{FIGURE LEGENDS}

Fig 1 Flowchart of participant inclusion

Fig 2 Hazard ratios $(\mathrm{HR})^{*}$ and their $95 \%$ confidence intervals $(95 \% \mathrm{Cl})$ for overweight $(\mathrm{BMI} \geq 25)$ duration and weighted cumulative overweight years (OWY), by cohort and cancer site, men and women combined.

* results from random-effects meta-analysis with adjustments for sex, smoking status, physical activity (yes/no), alcohol consumption and education level (Model 3)

a breast, colorectum, pancreas, kidney, gallbladder, endometrium, ovary, liver, lower oesophagus, cardia stomach

${ }^{b}$ pancreas, kidney, gallbladder, endometrium, ovary, liver, lower oesophagus, cardia stomach

Fig 3 Hazard ratios (HR) and their $95 \%$ confidence intervals $(95 \% \mathrm{Cl})$ for the association between (A) overweight (BMI $\geq 25$ ) duration, (B) weighted cumulative overweight years (OWY) and cancer risk, men and women combined

\footnotetext{
a breast, colorectum, pancreas, kidney, gallbladder, endometrium, ovary, liver, lower oesophagus, cardia stomach ${ }^{b}$ pancreas, kidney, gallbladder, endometrium, ovary, liver, lower oesophagus, cardia stomach

The figure shows a 3-knot spline of the relation between overweight duration and cancer risk, allowing for non-linear effects and adjusted for sex, study, smoking status and physical activity (Model 2). Restricted cubic splines very fitted with knots at $0,1,5$ and 10 years for overweight duration and at 0, 1, 13 and 65 for OWY. P-values are for non-linearity.
} 


\begin{tabular}{|c|c|c|c|c|c|c|c|c|c|c|c|c|c|c|c|c|}
\hline \multirow[b]{2}{*}{ Baseline characteristics } & \multicolumn{8}{|c|}{ EPIC-Elderly } & \multirow{2}{*}{\multicolumn{2}{|c|}{$\begin{array}{c}\text { Germany } \\
\text { (ESTHER) } \\
(n=8347) \\
\end{array}$}} & \multirow{2}{*}{\multicolumn{2}{|c|}{$\begin{array}{c}\text { Northern } \\
\text { Ireland (PRIME } \\
\text { Belfast) } \\
(n=1,920)\end{array}$}} & \multirow{2}{*}{\multicolumn{2}{|c|}{$\begin{array}{l}\text { Norway } \\
\text { (Troms } \emptyset \text { ) } \\
(n=5,849) \\
\end{array}$}} & \multirow{2}{*}{\multicolumn{2}{|c|}{$\begin{array}{c}\text { USA } \\
\text { (NIH AARP) } \\
(n=291,013) \\
\end{array}$}} \\
\hline & \multicolumn{2}{|c|}{$\begin{array}{l}\text { Denmark } \\
(n=6,871)\end{array}$} & \multicolumn{2}{|c|}{$\begin{array}{c}\text { Greece } \\
(n=6,877)\end{array}$} & \multicolumn{2}{|c|}{$\begin{array}{c}\text { Netherlands } \\
(n=4,149)\end{array}$} & \multicolumn{2}{|c|}{$\begin{array}{c}\text { Spain } \\
(n=4,550)\end{array}$} & & & & & & & & \\
\hline Recruitment year (range) & \multicolumn{2}{|c|}{ 1993-1997 } & \multicolumn{2}{|c|}{ 1994-1999 } & \multicolumn{2}{|c|}{ 1993-1997 } & \multicolumn{2}{|c|}{ 1992-1996 } & \multicolumn{2}{|c|}{$2000-2003$} & \multicolumn{2}{|c|}{ 1991-1994 } & \multicolumn{2}{|c|}{ 1994-1995 } & \multicolumn{2}{|c|}{ 1995-1997 } \\
\hline Mean age, in years (SD) & 62.5 & 1.5 & 67.0 & 4.4 & 64.3 & 2.8 & 62.5 & 1.7 & 61.8 & 6.6 & 54.2 & 2.8 & 59.4 & 6.9 & 62.2 & 5.3 \\
\hline \multicolumn{17}{|l|}{ Sex } \\
\hline Men & 3521 & $51.2 \%$ & 2693 & $39.2 \%$ & 154 & $3.7 \%$ & 1931 & $42.4 \%$ & 3784 & $45.3 \%$ & 1920 & $100.0 \%$ & 2736 & $46.8 \%$ & 173053 & $59.5 \%$ \\
\hline Women & 3350 & $48.8 \%$ & 4184 & $60.8 \%$ & 3995 & $96.3 \%$ & 2619 & $57.6 \%$ & 4563 & $54.7 \%$ & 0 & $0.0 \%$ & 3113 & $53.2 \%$ & 117960 & $40.5 \%$ \\
\hline \multicolumn{17}{|l|}{ Education } \\
\hline Low (primary or less) & 2451 & $35.7 \%$ & 6281 & $91.3 \%$ & 1279 & $30.8 \%$ & 3899 & $85.7 \%$ & 6025 & $72.2 \%$ & 15 & $0.8 \%$ & 2999 & $51.3 \%$ & 1391 & $0.5 \%$ \\
\hline Medium (more than primary but less than college) & 3040 & $44.2 \%$ & 379 & $5.5 \%$ & 2364 & $57.0 \%$ & 317 & $7.0 \%$ & 1736 & $20.8 \%$ & 1655 & $86.2 \%$ & 1710 & $29.2 \%$ & 64968 & $22.3 \%$ \\
\hline High (college or university) & 1366 & $19.9 \%$ & 200 & $2.9 \%$ & 503 & $12.1 \%$ & 284 & $6.2 \%$ & 412 & $4.9 \%$ & 250 & $13.0 \%$ & 1108 & $18.9 \%$ & 218567 & $75.1 \%$ \\
\hline Missing & 14 & $0.2 \%$ & 17 & $0.2 \%$ & 3 & $0.1 \%$ & 50 & $1.1 \%$ & 174 & $2.1 \%$ & 0 & $0.0 \%$ & 32 & $0.5 \%$ & 6087 & $2.1 \%$ \\
\hline Mean BMI at baseline (SD) & 26.1 & 3.8 & 29.3 & 4.3 & 25.8 & 3.9 & 29.5 & 4.0 & 27.6 & 4.2 & 26.1 & 3.2 & 26.1 & 3.7 & 26.8 & 4.5 \\
\hline Underweight (BMI < 18.5) & 35 & $0.5 \%$ & 18 & $0.3 \%$ & 45 & $1.1 \%$ & 4 & $0.1 \%$ & 33 & $0.4 \%$ & 8 & $0.4 \%$ & 43 & $0.7 \%$ & 2448 & $0.8 \%$ \\
\hline Normal weight (BMI $\geq 18.5$ \& BMI < 25) & 2819 & $41.0 \%$ & 1062 & $15.4 \%$ & 1891 & $45.6 \%$ & 491 & $10.8 \%$ & 2268 & $27.2 \%$ & 717 & $37.3 \%$ & 2352 & $40.2 \%$ & 105194 & $36.1 \%$ \\
\hline Overweight $(\mathrm{BMI} \geq 25 \& \mathrm{BMl}<30)$ & 3096 & $45.1 \%$ & 2997 & $43.6 \%$ & 1674 & $40.3 \%$ & 2151 & $47.3 \%$ & 3953 & $47.4 \%$ & 980 & $51.0 \%$ & 2634 & $45.0 \%$ & 123544 & $42.5 \%$ \\
\hline Obese $(\mathrm{BMI} \geq 30)$ & 921 & $13.4 \%$ & 2800 & $40.7 \%$ & 539 & $13.0 \%$ & 1904 & $41.8 \%$ & 2093 & $25.1 \%$ & 215 & $11.2 \%$ & 820 & $14.0 \%$ & 59827 & $20.6 \%$ \\
\hline Vigorous physical activitya & & & & & & & & & & & & & & & & \\
\hline Alcohol intake & & & & & & & & & & & & & & & & \\
\hline (average daily consumption in grams) & 20.2 & & 7.4 & & 7.8 & & 13.0 & & 6.8 & & 20 & & 3.6 & & 13.3 & \\
\hline $\mathrm{N}$ missing & 0 & $0.0 \%$ & 0 & $0.0 \%$ & 0 & $0.0 \%$ & 0 & $0.0 \%$ & 664 & $8.0 \%$ & 0 & $0.0 \%$ & 1082 & $18.5 \%$ & 0 & $0.0 \%$ \\
\hline Smoking status ${ }^{a}$ & & & & & & & & & & & & & & & & \\
\hline Never daily smoker & 2293 & $33.4 \%$ & 4830 & $70.2 \%$ & 2002 & $48.3 \%$ & 3095 & $68.0 \%$ & 4188 & $50.2 \%$ & 792 & $41.3 \%$ & 1935 & $33.1 \%$ & 106549 & $36.6 \%$ \\
\hline Former daily smoker & 2650 & $38.6 \%$ & 1257 & $18.3 \%$ & 1482 & $35.7 \%$ & 722 & $15.9 \%$ & 2771 & $33.2 \%$ & 637 & $33.2 \%$ & 2107 & $36.0 \%$ & 151248 & $52.0 \%$ \\
\hline Current daily smoker & 1928 & $28.1 \%$ & 790 & $11.5 \%$ & 665 & $16.0 \%$ & 733 & $16.1 \%$ & 1388 & $16.6 \%$ & 491 & $25.6 \%$ & 1807 & $30.9 \%$ & 33216 & $11.4 \%$ \\
\hline Hormone therapy use ${ }^{b}$ & & & & & & & & & & & & & & & & \\
\hline Ever & 1686 & $50.3 \%$ & 0 & $0.0 \%$ & 3299 & $82.6 \%$ & 2310 & $88.2 \%$ & 1965 & $43.1 \%$ & & /a & 1475 & $47.4 \%$ & 52021 & $44.1 \%$ \\
\hline Never & 1564 & $46.7 \%$ & 0 & $0.0 \%$ & 692 & $17.3 \%$ & 288 & $11.0 \%$ & 2287 & $50.1 \%$ & & /a & 873 & $28.0 \%$ & 65939 & $55.9 \%$ \\
\hline Missing & 100 & $3.0 \%$ & 4184 & $100.0 \%$ & 4 & $0.1 \%$ & 21 & $0.8 \%$ & 311 & $6.8 \%$ & & /a & 765 & $24.6 \%$ & 0 & $0.0 \%$ \\
\hline Self-reported or documented diabetes type 2 & & & & & & & & & & & & & & & & \\
\hline No & 6429 & $93.6 \%$ & 5924 & $86.1 \%$ & 3986 & $96.1 \%$ & 4026 & $88.5 \%$ & & a & & /a & & & 266601 & $91.6 \%$ \\
\hline Yes & 143 & $2.1 \%$ & 944 & $13.7 \%$ & 159 & $3.8 \%$ & 515 & $11.3 \%$ & & a & & /a & & a & 24412 & $8.4 \%$ \\
\hline Missing & 299 & $4.4 \%$ & 9 & $0.1 \%$ & 4 & $0.1 \%$ & 9 & $0.2 \%$ & & a & & la & & & 0 & $0.0 \%$ \\
\hline Median follow-up time (years) & & .9 & & 1.5 & & 3.2 & & .4 & & .4 & & 3.0 & & 9 & 10 & \\
\hline $\mathrm{N}$ cancers cases ( $\mathrm{N} /$ incidence ratec per 100000$)^{0}$ & 734 & & 340 & & 403 & & 483 & & 845 & & 256 & & 722 & & 53094 & \\
\hline $\mathrm{N}$ breast cancer (age>50, women only) & 110 & 42.4 & 21 & 9.3 & 109 & 57.0 & 42 & 21.4 & 120 & 86.0 & 0 & 0.0 & 64 & 39.1 & 5903 & 152.9 \\
\hline $\mathrm{N}$ colorectal cancer & 94 & 37.4 & 37 & 10.1 & 77 & 39.3 & 66 & 35.1 & 110 & 67.8 & 40 & 75.3 & 112 & 53.9 & 4469 & 93.5 \\
\hline $\mathrm{N}$ other obesity-related & 76 & 30.3 & 65 & 25.4 & 56 & 27.5 & 56 & 28.1 & 113 & 70.2 & 15 & 29.3 & 64 & 34.3 & 4701 & 104.7 \\
\hline
\end{tabular}

\footnotetext{
a participants with missing information on physical activity and smoking status were excluded; ${ }^{b}$ women only

${ }^{c}$ age-standardized to the World standard population; d pancreas, kidney, gallbladder, endometrium, ovary, liver, lower oesophagus, cardia stomach

e other obesity-related sites plus breast and colorectal cancer
} 
Table 2. Population attributable fractions (PAF) of ever being overweight (body mass index $\geq 25 \mathrm{~kg} / \mathrm{m} 2$ ) and cancer risk

\begin{tabular}{|c|c|c|c|c|c|c|c|c|c|}
\hline \multirow[b]{3}{*}{ Overall } & \multirow{3}{*}{$\begin{array}{l}\begin{array}{l}\% \text { ever } \\
\text { overweight }\end{array} \\
68.6 \%\end{array}$} & \multicolumn{2}{|c|}{$\begin{array}{l}\text { Obesity-related } \\
\text { cancers }^{\mathrm{a}}\end{array}$} & \multicolumn{2}{|c|}{ Breast cancer } & \multicolumn{2}{|c|}{ Colorectal cancer } & \multicolumn{2}{|c|}{$\begin{array}{l}\text { Other obesity-related } \\
\text { cancers }^{b}\end{array}$} \\
\hline & & \multicolumn{2}{|c|}{ PAF (95\% Cl) } & \multicolumn{2}{|c|}{ PAF (95\% Cl) } & \multicolumn{2}{|c|}{ PAF (95\% Cl) } & \multicolumn{2}{|c|}{ PAF (95\% Cl) } \\
\hline & & $8.4 \%$ & $(6.3-10.5)$ & & & $9.6 \%$ & $(5.3-13.8)$ & $19.4 \%$ & $(15.5-23.1)$ \\
\hline Men & $75.0 \%$ & $20.0 \%$ & $(15.7-24.0)$ & & & $13.3 \%$ & $(7.3-18.9)$ & $28.2 \%$ & $(22.1-33.9)$ \\
\hline Women & $60.0 \%$ & $4.6 \%$ & $(2.2-6.9)$ & * & * & * & * & $13.0 \%$ & (8.1-17.6) \\
\hline Current daily smoker & $59.1 \%$ & * & * & * & * & * & * & $9.9 \%$ & $(0.5-18.4)$ \\
\hline Former daily smoker & $72.2 \%$ & $8.8 \%$ & $(5.5-12.0)$ & * & * & $8.7 \%$ & $(2.2-14.8)$ & $22.1 \%$ & $(16.2-27.6)$ \\
\hline Never daily smoker & $67.1 \%$ & $10.1 \%$ & $(6.7-13.4)$ & * & * & $15.2 \%$ & (8.0-21.8) & $19.7 \%$ & $(13.4-25.6)$ \\
\hline Diabetes ever & $85.8 \%$ & $17.5 \%$ & $(5.0-28.3)$ & * & * & * & * & $42.1 \%$ & $(24.1-55.9)$ \\
\hline Diabetes never & $66.7 \%$ & $6.9 \%$ & $(4.7-9.1)$ & * & * & $8.6 \%$ & $(4.0-13.0)$ & $16.3 \%$ & $(12.2-20.2)$ \\
\hline HRT ever users & $54.7 \%$ & * & * & * & * & * & * & * & * \\
\hline HRT never users & $63.7 \%$ & $15.6 \%$ & $(11.8-19.2)$ & $17.9 \%$ & $(12.6-22.8)$ & * & * & $23.3 \%$ & $(16.1-29.8)$ \\
\hline
\end{tabular}

a breast, colorectum, pancreas, kidney, gallbladder, endometrium, ovary, liver, lower oesophagus, cardia stomach

b pancreas, kidney, gallbladder, endometrium, ovary, liver, lower oesophagus, cardia stomach

*PAF not calculated because HR statistically non-significant. 